\title{
Utilisation of outpatient physiotherapy in patients following total knee arthroplasty - a systematic review
}

\author{
Hannes Jacobs ${ }^{1 *}$, Gesine H. Seeber ${ }^{2,3}$, Katharina Allers ${ }^{1}$ and Falk Hoffmann ${ }^{1}$
}

\begin{abstract}
Objective: Data on the utilisation of outpatient physiotherapy (PT) in patients following total knee arthroplasty (TKA) are scarce, and available studies have not been systematically synthesised. This study aims to summarise the existing literature on outpatient PT following TKA as well as to identify factors associated with its use.

Methods: A systematic literature search in MEDLINE (via PubMed), CINAHL, Scopus and PEDro was conducted in July 2020 without language restrictions. Two authors independently selected studies, extracted data and assessed study quality. The primary outcome was the proportion being treated with at least one session of outpatient PT (land- or water-based treatments supervised/provided by a qualified physiotherapist) during any defined period within 12 months following TKA. Furthermore, predictors for the use of PT were assessed. Studies including only revision surgeries or bilateral TKA were excluded.
\end{abstract}

Results: After screening 1934 titles/abstracts and 56 full text articles, 5 studies were included. Proportions of PT utilisation ranged from 16.7 to $84.5 \%$. There were large variations in the time periods after hospital discharge (4 weeks to 12 months) and in the reporting of PT definitions. Female sex was associated with higher PT utilisation, and compared to patients after total hip arthroplasty, utilisation was higher among those following TKA.

Conclusion: Despite using a broad search strategy, we found only 5 studies assessing the utilisation of PT after hospital discharge in patients with TKA. These studies showed large heterogeneity in PT utilisation, assessed time periods and PT definitions. Clearly, more studies from different countries with uniform PT definitions are needed to address this relevant public health question.

Keywords: Physical therapy, Rehabilitation, Osteoarthritis, Health services research, Arthroplasty

\section{Background}

Osteoarthritis (OA) is the most common joint disorder and a leading cause of disability in older adults $[1,2]$. It is a progressive condition associated with pain, movement restrictions and, as a result, diminished quality of life $[3,4]$. Treatment of OA aims to manage symptoms and increase mobility, but at present there is no cure for

\footnotetext{
*Correspondence: Hannes.Jacobs@uol.de

'Department of Health Services Research, Carl von Ossietzky University Oldenburg, Ammerländer Heerstr. 114-118, 26129 Oldenburg, Germany Full list of author information is available at the end of the article
}

this syndrome. For severe OA that no longer responds to medication and physiotherapy (PT) including exercise, clinical guidelines recommend total knee arthroplasty (TKA) as a cost-effective intervention [5-7]. This is one of the most frequently performed surgeries in industrialised countries $[8,9]$, and $\mathrm{OA}$ is by far the main indication for this procedure $[8,10,11]$. Due to demographic change and growing obese populations in high-income countries, rising OA prevalence as well as an increasing number of TKAs is to be expected [12-14].

C C The Author(s). 2021 Open Access This article is licensed under a Creative Commons Attribution 4.0 International License, which permits use, sharing, adaptation, distribution and reproduction in any medium or format, as long as you give appropriate credit to the original author(s) and the source, provide a link to the Creative Commons licence, and indicate if changes were made. The images or other third party material in this article are included in the article's Creative Commons licence, unless indicated otherwise in a credit line to the material. If material is not included in the article's Creative Commons licence and your intended use is not permitted by statutory regulation or exceeds the permitted use, you will need to obtain permission directly from the copyright holder. To view a copy of this licence, visit http://creativecommons.org/licenses/by/4.0/ The Creative Commons Public Domain Dedication waiver (http://creativecommons.org/publicdomain/zero/1.0/) applies to the data made available in this article, unless otherwise stated in a credit line to the data. 
TKAs are highly successful in restoring joint function and relieving pain, and they are associated with high patient satisfaction [15]. However, despite good results following surgery, a considerable proportion of patients undergoing TKA experience an unfavourable outcome. In a systematic review of prospective studies in unselected patients, 10 to $34 \%$ reported chronic pain between 3 months and 5 years after surgery [16]. Jones et al. observed $20 \%$ of patients with unfavourable pain outcomes at 6 months in a high-quality study in multiple centres with low loss to follow-up [17]. However, the exact percentage of patients with chronic pain and/or decreased function is unclear and varies across studies [16].

Physiotherapy, aiming to improve muscle strength, neuromotor control and range of joint motion [18] can be an effective treatment after TKA to help prevent unfavourable outcomes $[19,20]$. Patients can receive various health care services that might also include $\mathrm{PT}$ in settings ranging from inpatient rehabilitation facilities to outpatient private practices and telerehabilitation. In (inpatient) acute care settings, PT is a routine component of postoperative management [19, 21 ] and can help to achieve a higher range of motion (ROM), reduce pain, and decrease the length of hospital stay [22]. Evaluating post-discharge rehabilitation in a systematic review, Artz et al. found improved physical function and pain at 3-4 months after surgery. Considering only higher quality studies, the benefit was apparent even up to 6 months [20]. However, although a Delphi study from Canada and the United States [23] published in 2014 already recommended PT for post-acute or post-discharge rehabilitation after TKA, rehabilitation programs currently vary greatly, and no clear prevailing evidence-based practice guidelines are available [24, 25]. Westby et al. call for supervised rehabilitation interventions provided by trained health professionals early after discharge from the acute care setting. In addition, regular follow-up visits with medical professionals (including PTs) in the late post-surgical phase (3-12 months) or even in the first 2 years following TKA is desirable to optimise patient outcomes [23].

Utilisation of PT prior to TKA was assessed by several studies. These studies found that 44 to $73 \%$ received PT prior to TKA [26-30] and that female sex [26-30], younger age [30] and higher education [30] were associated with an increased use of PT. After TKA, most studies were conducted in acute care settings, where PT is routinely used [19]. These studies often focus on differences in type, number and duration of PT and found that rehabilitation practice varies widely [19, 20]. However, data on the utilisation of outpatient PT in patients following TKA after acute care or inpatient rehabilitation are scarce, and the available studies have not been systematically synthesised (e.g. in terms of prevalence and factors associated with PT use).

Therefore, this study aims to summarise the existing literature regarding the proportion of patients receiving outpatient PT following TKA as well as to identify factors associated with its use.

\section{Materials and methods}

A protocol for this systematic review was registered with PROSPERO (CRD42020197301). Furthermore, we followed the Preferred Reporting Items for Systematic Reviews and Meta-Analyses (PRISMA) statement [31].

\section{Data sources and search}

The literature search was performed in the databases MEDLINE (via PubMed), CINAHL, Scopus and PEDro (see Additional file 1 for search strategy). We searched the electronic databases from inception to 09 July 2020. Additionally, we scanned the reference lists of all included studies.

\section{Eligibility criteria}

We defined study eligibility criteria using the CoCoPop (condition, context, and population) approach for reviews assessing prevalence and incidence data [32, 33].

\section{Condition}

We included studies reporting on proportions of patients receiving at least one session of outpatient PT during any defined period (e.g. 6 weeks, 6 months or 12 months) in the early phase ( $\leq 12$ months) following TKA. We defined PT as land- or water-based treatments supervised or provided by a qualified physiotherapist regardless of content, duration, frequency or intensity. Therefore, studies assessing other forms of therapy not advised or provided by a qualified physiotherapist were not considered. Furthermore, studies reporting only mean amounts of treatments without proportions were excluded.

\section{Context}

We included studies providing information on the use of PT during the rehabilitative period after hospital discharge following TKA surgery to the outpatient, community, or home setting. There was no exclusion based on special settings (e.g. nursing homes), but we excluded studies reporting on inpatient PT such as in acute hospitals or inpatient rehabilitation facilities.

\section{Population}

Studies reporting on patients who underwent unilateral or bilateral TKA were included. Studies including only revision surgeries or bilateral TKA were not considered eligible. There were no restrictions regarding the type of 
hospital (community (general), teaching, rural, urban, or federal government hospital) or the number of hospitals from which participants were recruited. There were no limitations regarding age, sex or functional status of included patients, but we excluded studies that were limited to specific diagnoses beyond osteoarthritis (e.g. rheumatoid arthritis).

We included published observational and interventional studies. To be included, interventional studies had to fulfil one of the following conditions: [1] If information on outpatient PT was reported at follow up for patients recruited during index hospitalisation for TKA and placed in the control group (treatment as usual/ usual care), we included the control arm [2]. If patients were recruited in any period within the first 12 months following TKA and the utilisation of outpatient PT after TKA was reported at baseline, both the intervention group and the control group were included. We excluded $\mathrm{PhD}$ theses and studies or the respective study arm in interventional studies with a sample size $<100$ to ensure robust results. No other limitations, such as language, year or location of publication, were applied.

\section{Study selection and data extraction}

Results from the literature search were exported into an EndNote (Version X9, Clarivate, Philadelphia, PA, USA) library, and duplicates were removed. Two of the authors independently screened articles based on title and abstract to determine inclusion or exclusion. Disagreement was resolved by discussion or by a third reviewer. Subsequently, the full text of all articles meeting the criteria was assessed by the two reviewers, and if necessary, any discrepancy was again solved by discussion or by a third reviewer.

We abstracted data on study characteristics (country, data source, year of data, sample size, number of hospitals, eligibility criteria), patient characteristics (mean age, sex) and outcome results (definition of PT, proportion of being treated with PT, period after hospital discharge, and factors affecting / predictors for the use of PT). Data extraction was performed by one reviewer and verified by a second. Discrepancies were resolved by discussion or by a third reviewer.

\section{Quality assessment}

To assess the quality of the included studies, we chose the Joanna Briggs Institute's (JBI) critical appraisal checklist for studies reporting prevalence data. It includes nine items [32] and is very flexible across different study designs [34]. Two reviewers independently assessed the quality of included studies. Any disagreement was resolved by discussion or a third reviewer. The assessed study quality had no impact on the inclusion or exclusion of studies.

\section{Data synthesis}

We analysed the results using a narrative synthesis. Due to the expected heterogeneity between studies, a metaanalysis was not planned. Differences in PT utilisation by age, sex, socioeconomic status (SES) or physical function were analysed to the extent they were reported (irrespective of whether proportions were provided for these subgroups or whether variables were included in regression models). Additionally, reported information on other factors influencing the use of PT was assessed.

Beyond that, we aimed to compare PT use data from studies which also included patients following primary total hip arthroplasty (THA).

\section{Results}

\section{Literature search}

The screening of 1934 titles/abstracts and 56 full text articles identified six studies fulfilling the inclusion criteria [35-40]. As two articles [37, 40] referred to the same study and data, we included only one of them [37]. Therefore, five full texts were finally included in the review [35-39] (Fig. 1). Four studies were reported in English and one in Danish.

\section{Study characteristics}

Baseline characteristics of the five included studies are shown in Table 1. Two studies were conducted in the United Kingdom [36, 38] and one each in Denmark [35], Australia [37], and the United States [39]. Four studies used a longitudinal cohort design (two prospective and two retrospective), and one study used a randomised controlled trial design.

The studies were published between 2009 and 2020, and the data were generated between 2006 and 2015 . Use of PT was assessed in a variety of ways, with studies obtaining utilisation data from self-reported questionnaires, study-specific diaries, claims data, or registries. The sample size ranged from 102 to 20,260, and the number of hospitals in which participants underwent surgery ranged from 1 to 2664. One study did not report on the number of hospitals.

All studies reported data on patients' age and sex. Females were in the majority in all five studies, with their proportion varying from 53 to $62 \%$. Patients' mean age ranged from 65 to 71 years.

\section{Methodological quality of included studies}

The quality assessment for each study is presented in Table 2. Overall, in four of the five studies, the sample frame was appropriate for addressing the target population. In two studies, the sample size was inadequate. Another two studies did not conduct data analysis with sufficient coverage of the identified sample. Three of the five included studies identified the utilisation of PT with valid methods. 


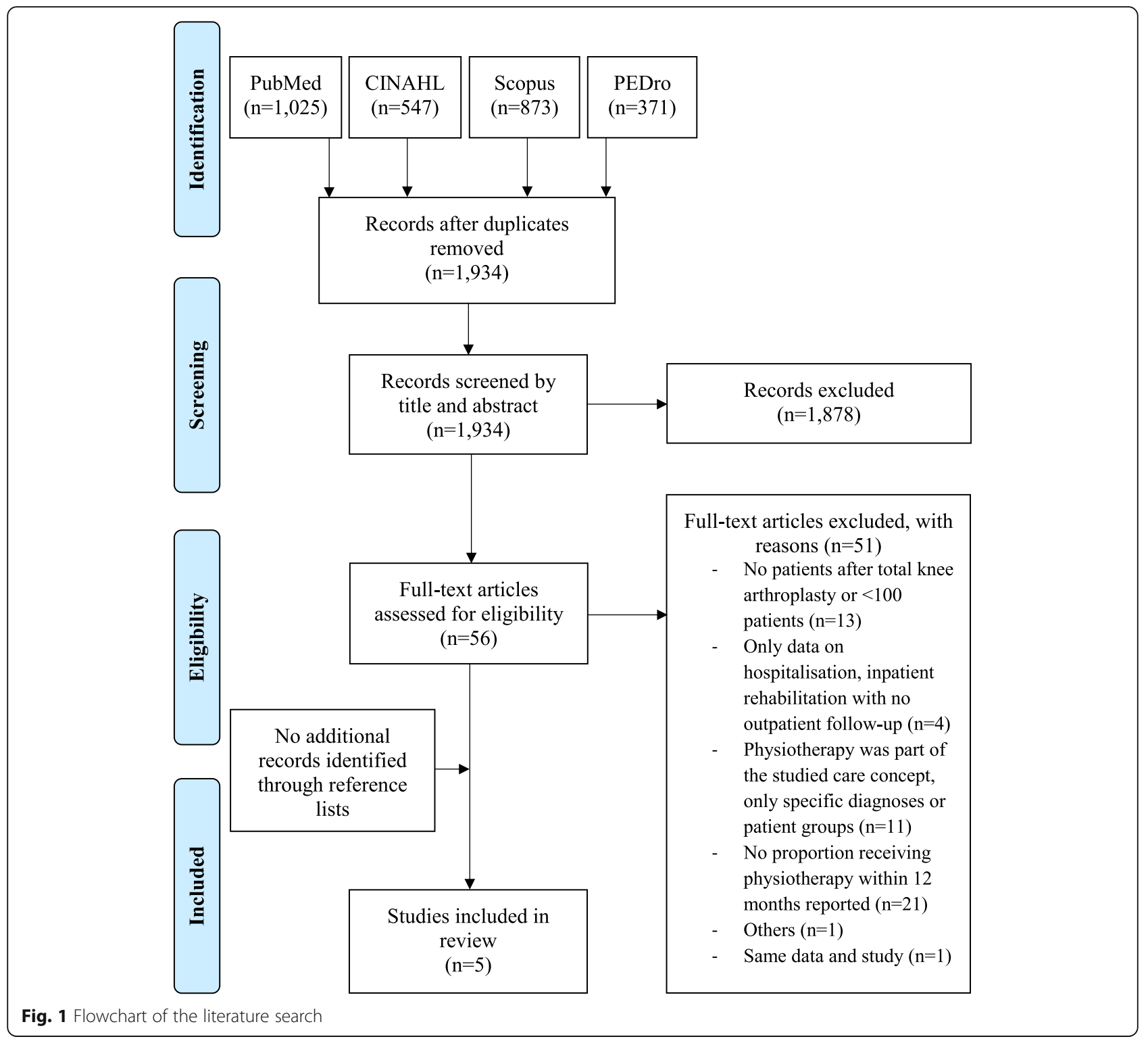

\section{Utilisation of outpatient PT following TKA}

The definition of PT varied between studies and is presented in Table 3. One study defined PT as the proportion of patients visiting a physiotherapist (data extracted from a health insurance register), [35] and one study as provision (yes/no) of PT in a self-reported questionnaire [38]. A third study defined PT as billing codes used only by physical therapists [39]. Two studies did not report any definition of PT [36, 37].

The time period after hospital discharge for which utilisation of PT was observed differed between all included studies and ranged from four [39] and 6 weeks [37] to three [35], six [36] and twelve [38] months. Likewise, the proportion of $\mathrm{PT}$ utilisation varied widely. The highest proportion of outpatient PT following TKA was observed in Australia, at $84.5 \%$ within the first 6 weeks after hospital discharge [37]. A similar proportion was reported by Smith et al. in the United Kingdom (79.0\%) [38]. However, this proportion referred to the first year after discharge. The other study from the United Kingdom observed a utilisation of $48.2 \%$ within 6 months [36]. Warren et al. reported a proportion of $40.4 \%$ within 4 weeks in the United States [39]. The lowest proportion was found in the Danish study [35], which reported an outpatient utilisation of PT following TKA of $16.7 \%$ in the first 3 months after hospital discharge.

\section{Predictors for the use of PT}

Two studies reported on the influence of sex on the use of PT following TKA (Table 3). Hamilton et al. [36] observed a higher proportion of PT utilisation in females 


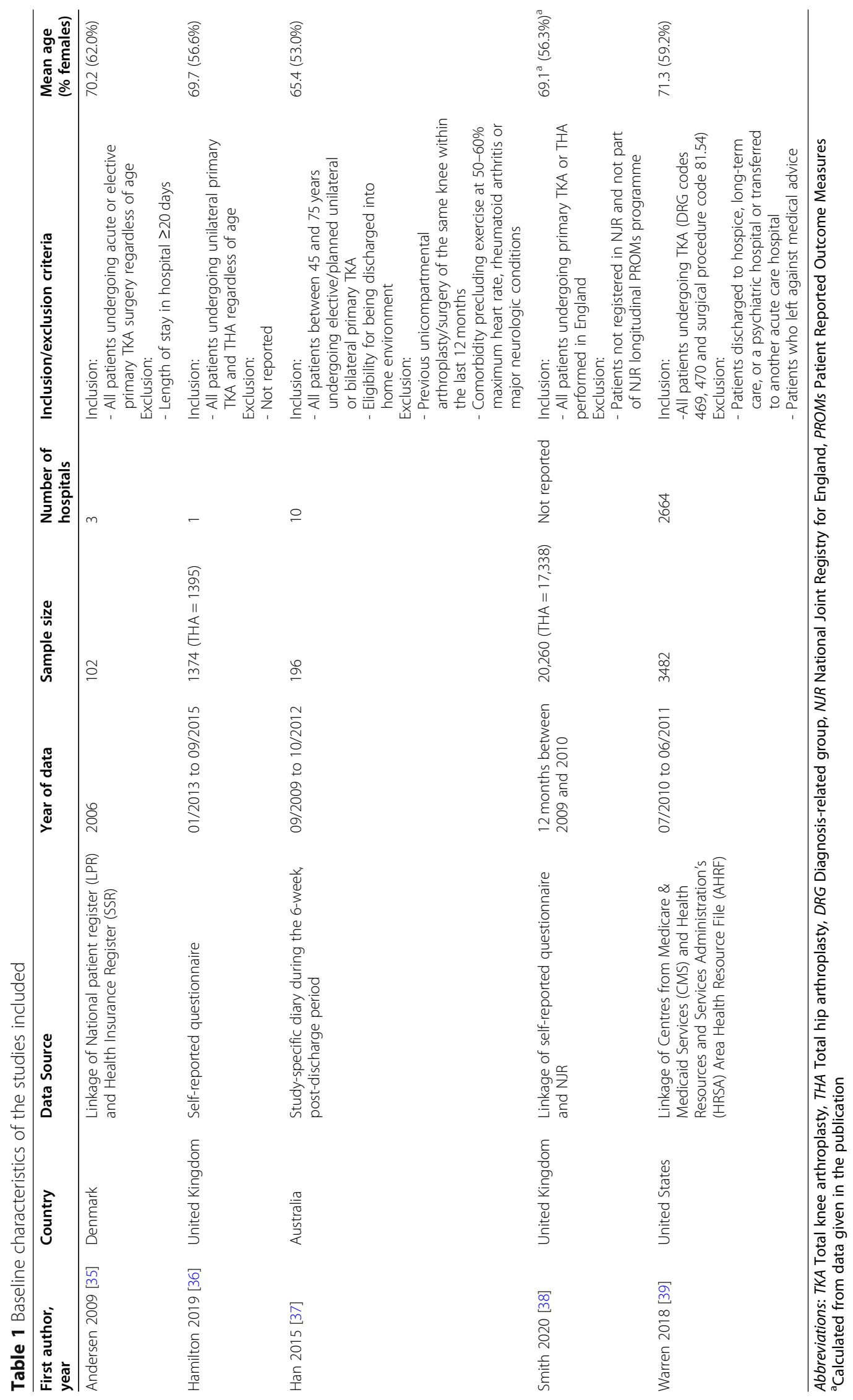


Table 2 Summary of quality assessment

\begin{tabular}{llllllllll}
\hline First author, year & $\mathbf{1}$ & $\mathbf{2}$ & $\mathbf{3}$ & $\mathbf{4}$ & $\mathbf{5}$ & $\mathbf{6}$ & $\mathbf{7}$ & $\mathbf{8}$ & $\mathbf{9}$ \\
\hline Andersen 2009 [35] & Yes & Yes & No & No & Yes & Yes & Yes & No & Yes \\
Hamilton 2019 [36] & Yes & Yes & Yes & Yes & Yes & No & Yes & Yes & Yes \\
Han 2015 [37] & No & Yes & No & Yes & No & Yes & Yes & Yes & Yes \\
Smith 2020 [38] & Yes & Yes & Yes & Yes & Yes & No & Yes & Yes & Yes \\
Warren 2018 [39] & Yes & Yes & Yes & Yes & No & Yes & Yes & Yes & N/A
\end{tabular}

Quality appraisal criteria [32]:

1) Was the sample frame appropriate to address the target population?

2) Were the study participants sampled in an appropriate way?

3) Was the sample size adequate?

4) Were the study subjects and the setting described in detail?

5) Was the data analysis conducted with sufficient coverage of the

identified sample?

6) Were valid methods used for the identification of the condition?

7) Was the condition measured in a standard, reliable way for all participants?

8) Was there appropriate statistical analysis?

9) Was the response rate adequate, and if not, was the low response rate managed appropriately?

Abbreviations: N/A Not applicable

compared to males $(50.1 \%$ vs. $45.6 \%$ in the first 6 months), which was also confirmed in a multivariate logistic regression (OR: 1.26; 95\% CI 1.01-1.58). Smith et al. [38] also reported a greater proportion of women using PT after hospital discharge $(80.4 \%$ vs. $77.7 \%$ in the first twelve months).

Hamilton et al. was the only study reporting on the influence of age, finding that PT utilisation decreased with age (OR per year age decrease: 1.04; 95\% CI 1.02-1.05) [36].

None of the studies reported frequencies regarding SES or physical function or included these variables in a regression model.

Further predictors influencing PT utilisation were reported by Andersen et al. [35] (type of hospital ward) and Smith et al. [38] (ethnicity, living arrangements, American Society of Anesthesiologists (ASA) grade, and number of comorbidities).

Hamilton et al. and Smith et al. further provided information on differences between PT users and non-PT users (e.g. regarding social deprivation (based on postcodes) or physical function (mean values of the metric Oxford Knee Score (OKS)), making it impossible to calculate PT use proportions) [36, 38], which was, however, outside the scope of this review.

\section{Comparison of PT utilisation in TKA versus THA}

Two studies also reported on the proportion of outpatient PT following THA. Compared to TKA, PT utilisation following THA was lower in both studies, at $48.2 \%$ vs. $35.3 \%$ within the first 6 months after hospital discharge [36] and $79.0 \%$ vs. $53.0 \%$ within the first twelve months [38] (Table 3).

Hamilton et al. [36] also conducted a multivariate logistic regression model for PT use after THA. The influence of sex was higher in THA patients (OR: 1.60; 95\%
CI 1.27-2.03) than in TKA patients (OR: 1.26; 95\% CI 1.01-1.58), while the influence of age did not differ (TKA: OR: 1.04 ; $95 \%$ CI $1.02-1.05$ vs. THA: OR: 1.03 ; 95\% CI 1.02-1.04). Furthermore, quality of life (measured by EQ-5D) was a predictor for PT utilisation in THA patients (OR: 1.54; CI 95\% 1.08-1.20) but not in TKA patients.

\section{Discussion}

This review aimed to systematically examine the existing literature regarding the utilisation of outpatient PT following TKA. Five studies assessing different time periods met the inclusion criteria. We found large variations in the proportions of PT use, ranging from 16.7 to $84.5 \%$. Furthermore, two studies analysed predictors for the use of PT following TKA and found that female sex was associated with higher utilisation. In the two studies comparing to patients after THA, utilisation of PT was higher among those following TKA.

Surprisingly, only a very small number of studies is available on this question of high public health relevance. TKA is one of the most frequent surgeries in industrialised countries $[8,9]$, and a considerable proportion of patients undergoing TKA experience unfavourable outcomes such as chronic pain or a diminished range of motion [16]. High-quality evidence suggests that PT can be an effective treatment following TKA to help prevent those complications $[19,20]$. However, for most industrialised countries, it is unclear to what extent these evidence-based recommendations are consistently implemented.

Furthermore, each of the five available studies assessed different time periods, ranging from four weeks to twelve months after hospital discharge, but none of the studies justified why the respective period was chosen. These varying time periods in which PT utilisation was studied might be explained by a focus on primary outcomes other than PT utilisation [35] or by differences in rehabilitation pathways between countries. Patients can receive various inpatient and outpatient services that might include PT at facilities such as specialised inpatient rehabilitation centres, skilled nursing home facilities, outpatient facilities, private practices or in homebased programs. In terms of inpatient rehabilitation following surgery, referral rates vary widely between countries. In the United Kingdom, inpatient rehabilitation is quite uncommon following TKA [41], and in Canada, the referral rate is also low (7.7\%) [42]. The proportions of patients being discharged to an inpatient rehabilitation facility after TKA are higher in the United States. In a rapid review, a median of $26.0 \%$ was transferred to an inpatient rehabilitation facility and a further $23.8 \%$ to a skilled nursing facility [43]. Another study showed that $53.4 \%$ of TKA patients were discharged from hospital to 


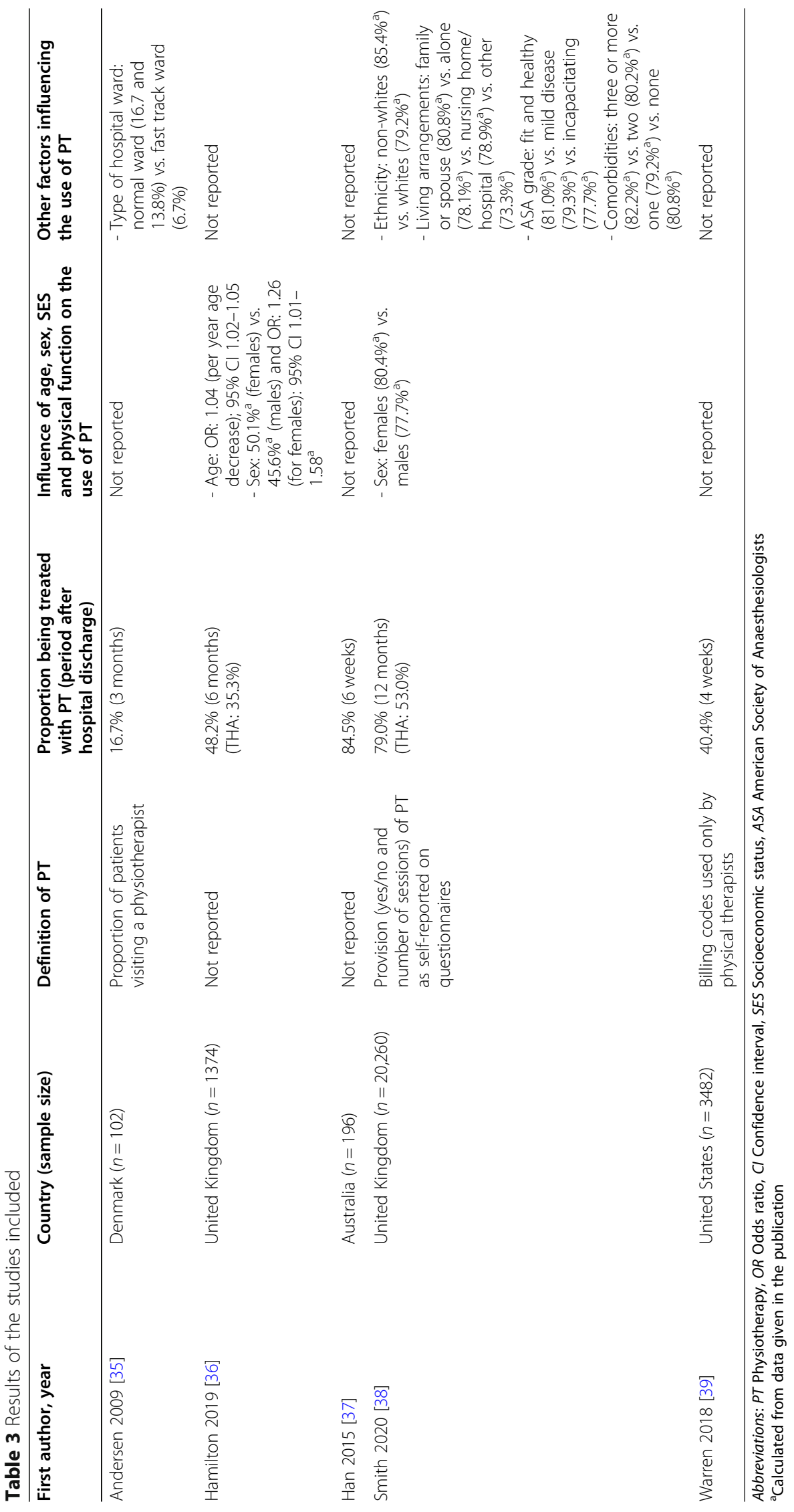


a type of inpatient facility [44]. Even higher proportions are observed in Germany, where the acute care of TKA or THA patients is usually followed by 3 weeks of inpatient rehabilitation [45]. For example, Füssenich et al. reported that $72 \%$ of THA patients underwent inpatient rehabilitation following surgery [46].

Moreover, differences in the utilisation and intensity of outpatient rehabilitation exist between countries. For example, in Canada and the United Kingdom, the vast majority of TKA patients are transferred directly home after hospital discharge $[41,42]$. In the United States, the above-mentioned rapid review showed a median of $34.1 \%$ being discharged home with supervision, but at a wide range from 0.6 to $44.2 \%$ [42]. In Germany, Füssenich et al. observed that $20 \%$ of THA patients receive outpatient rehabilitation for 3 weeks, where they have 4-6h of therapeutic interventions per day [46]. Outpatient PT can also be used alongside or after specific rehabilitation services. For example, in the United Kingdom, where inpatient and outpatient rehabilitation are quite uncommon, the two included studies by Hamilton [36] (48.6\% within 6 months) and Smith [38] (79.0\% within 12 months) found a comparably high use of outpatient PT after TKA. In Australia, about $80 \%$ of patients are referred home, which also might explain the high proportion of outpatient PT (84.5\% within 6 weeks) [37]. These considerable differences in policies and care pathways between countries have to be considered when interpreting our results.

Another factor reducing the comparability of studies on outpatient PT use following TKA is that definitions of PT are inconsistent across studies. Two of the five included studies did not even report any definition of PT $[36,37]$. This is a crucial point as PT can include quite different interventions from land- and water-based group exercises to one-on-one treatments such as therapeutic exercise and manual therapy. Moreover, some types of PT interventions (e.g. electrotherapy or thermotherapy) also involve the use of specific tools. Besides the types of interventions, their frequency as well as their intensity might differ. In this review, only one of the included studies reported on frequency, e.g. in terms of numbers of PT sessions [38]. None of the included studies assessed PT intensity, despite the fact that treatment duration and number of repetitions might vary depending on the therapeutic goals [47]. Some studies assessing home health services utilisation might have included PT - amongst others - but not have reported on it separately. Inconsistent PT and exercise definitions were also used in reviews on other indications, including musculoskeletal [48-51] and neurological disorders [52, 53]. These inconsistencies hamper not only the comparability between studies but also the evaluation of appropriateness of care [54].
Overall, two of the five included studies analysed the influence of sex on outpatient PT utilisation following TKA [36, 38]. Both studies found higher utilisation in women than in men. This is in line with many other studies assessing PT utilisation in different populations like OA patients [55], rheumatoid arthritis patients [56], knee OA patients prior to TKA $[26,27]$, or even the general population [57]. Age is another parameter that is discussed as a factor influencing the utilisation of PT. As the only study in this review reporting on this factor, Hamilton et al. [36] found decreasing PT utilisation with age, in line with other studies on PT in musculoskeletal disorders [58]. However, results are inconsistent. Other studies in OA patients showed no association between younger age and PT but less frequent utilisation in the elderly $(>65)[55,59]$ or no association at all $[26,60]$. None of the included studies assessed functional status and SES as factors influencing PT utilisation. The current literature provides evidence of an impact of higher SES on the utilisation of PT in the general population [57] and in OA patients $[59,60]$ as well as an influence of lower functional status $[60,61]$.

Functional status might also be the reason why both included studies comparing TKA to THA patients found higher PT utilisation following TKA $[36,38]$. The more complicated anatomy of the knee joint might result in a higher proportion of complications following arthroplasty [16], which is in line with numerous studies reporting inferior function and clinical outcomes for TKA patients [62-66]. For example, de Beer et al. surveyed patients who had undergone both primary unilateral TKA and THA, with a mean interval of 2.6 months between the first and second joint replacement. They found postoperatively greater pain levels, greater difficulty in ambulating, and greater difficulty performing activities of daily life after TKA, resulting in a longer period to achieve a satisfactory recovery status and a higher need for PT [66].

\section{Strengths and limitations}

This is the first systematic review summarising the existing evidence on the proportion of outpatient PT utilisation following TKA. However, there are some limitations that have to be considered. We might have missed studies that did not focus on PT utilisation but mentioned such a proportion in the full text or were not listed in the classic medical databases. However, in order to minimise this risk, we used a comprehensive search strategy, and full texts were screened even if there was just a minimal chance of reported PT utilisation. In addition, we searched references lists of included studies and did not use any language restrictions. Some studies reported only specific treatments [44] or solely the absolute number of PT sessions [67], making it impossible to calculate 
the overall prevalence of PT utilisation. These studies might have assessed the proportion of PT but did not report them. Another aspect to be taken into account when interpreting our results is that the included studies are very heterogenous in terms of sample size, number of hospitals and in the way PT utilisation was assessed. Additionally, some included studies are of lower quality regarding, e.g., the conduct of data analysis with sufficient coverage of the identified sample, adequate sample size or using valid methods for the identification of PT utilisation. However, we performed quality appraisal using the JBI tool recommended for systematic reviews of studies on prevalence [32] and explained its results transparently. Furthermore, this heterogeneity is not a weakness of our approach but represents limitations of the included studies themselves. Results of this systematic review therefore provide a comprehensive overview of the evidence published worldwide on outpatient PT utilisation following TKA.

\section{Conclusion}

In this systematic review using a broad search strategy without language restrictions, we found only five studies assessing the utilisation of outpatient PT after hospital discharge in patients with TKA, and only two of these studies also analysed predictors. The large differences in the proportions of patients using outpatient PT in any time period within the first year after TKA (ranging from 16.7 to 84.5\%) might be explained by the different time periods assessed and by differences in care pathways between countries. Therefore, more studies on this relevant public health question from different countries are clearly needed; these studies should be large enough to analyse potential differences by age, sex, SES and physical function in order to provide the basis for clinical decisions and to identify potential groups that are prone to underutilisation. Furthermore, future studies ought to use uniform PT definitions or at least report their operationalisation as well as justifications for time periods assessed and should also describe frequency, intensity and types of interventions.

\footnotetext{
Abbreviations

AHRF: Area Health Resource File; ASA: American Society of

Anaesthesiologists; CMS: Centres from Medicare \& Medicaid Services; $\mathrm{Cl}$ : Confidence interval; CoCoPop: Condition, Context, and Population; DRG: Diagnosis-related group; HRSA: Health Resources and Services Administration's; JBI: Joanna Briggs Institute; LPR: National patient register; NJR: National Joint Registry for England; OA: Osteoarthritis; OKS: Oxford Knee Score; OR: Odds ratio; PRISMA: Preferred Reporting Items for Systematic Reviews and Meta-Analyses; PROMs: Patient Reported Outcome Measures; PT: Physiotherapy; ROM: Range Of motion; SES: Socioeconomic status; SSR: Health Insurance Register; THA: Total Hip Arthroplasty; TKA: Total Knee Arthroplasty
}

\section{Supplementary Information}

The online version contains supplementary material available at https://doi. org/10.1186/s12891-021-04600-2.

Additional file 1. Search strategy.

\section{Acknowledgements}

Not applicable.

\section{Conflict of interest}

The authors declare no conflict of interest.

\section{Authors' contributions}

$\mathrm{HJ}$ and FH contributed to the study concept, design, data analysis and manuscript writing. KA was involved in the study concept, design and data analysis. GS contributed to data collection and analysis. All authors were involved in drafting the article or revising it critically for important intellectual content, and all authors approved the final version of the manuscript.

\section{Funding}

This work is supported by intramural funding of the School of Medicine and Health Sciences of the Carl von Ossietzky University Oldenburg (FP 2018026). Open Access funding enabled and organized by Projekt DEAL.

Availability of data and materials

All data generated or analysed during this study are included in this published article.

\section{Declarations}

Ethics approval and consent to participate

Not applicable.

Consent for publication

Not applicable.

\section{Competing interests}

The authors declare that they have no competing interests.

\section{Author details}

${ }^{1}$ Department of Health Services Research, Carl von Ossietzky University Oldenburg, Ammerländer Heerstr. 114-118, 26129 Oldenburg, Germany. ${ }^{2}$ University Hospital for Orthopaedics and Trauma Surgery Pius-Hospital, Medical Campus University of Oldenburg, Oldenburg, Germany. ${ }^{3}$ Department of Orthopedics, University of Groningen, University Medical Center Groningen, Groningen, The Netherlands.

Received: 27 May 2021 Accepted: 3 August 2021

Published online: 18 August 2021

\section{References}

1. Woolf AD, Pfleger B. Burden of major musculoskeletal conditions. Bull World Health Organ. 2003;81(9):646-56.

2. Cross M, Smith E, Hoy D, Nolte S, Ackerman I, Fransen M, et al. The global burden of hip and knee osteoarthritis: estimates from the global burden of disease 2010 study. Ann Rheum Dis. 2014;73(7):1323-30. https://doi.org/1 0.1136/annrheumdis-2013-204763.

3. Martel-Pelletier J, Barr AJ, Cicuttini FM, Conaghan PG, Cooper C, Goldring MB, et al. Osteoarthritis. Nat Rev Dis Prim. 2016;2(1). https://doi.org/10.1038/ nrdp.2016.72.

4. Storheim K, Zwart J-A. Musculoskeletal disorders and the global burden of disease study. Ann Rheum Dis. 2014;73(6):949-50. https://doi.org/10.1136/a nnrheumdis-2014-205327.

5. RACGP - Guideline for the management of knee and hip osteoarthritis. https://www.racgp.org.au/download/Documents/Guidelines/Musculoskeleta I/guideline-for-the-management-of-knee-and-hip-oa-2nd-edition.pdf. Published 2018. Accessed 19 Aug 2020.

6. Ethgen $\mathrm{O}$, Bruyerè $\mathrm{O}$, Richy F, Dardennes $\mathrm{C}$, Reginster JY. Health-related quality of life in Total hip and Total knee arthroplasty: a qualitative and 
systematic review of the literature. J Bone Jt Surg - Ser A. 2004;86(5):963-74. https://doi.org/10.2106/00004623-200405000-00012.

7. Jones CA, Beaupre LA, Johnston DWC, Suarez-Almazor ME. Total joint arthroplasties: current concepts of patient outcomes after surgery. Rheum Dis Clin N Am. 2007;33(1):71-86. https://doi.org/10.1016/j.rdc.2006.12.008.

8. Australian Orthopaedic Association National Joint Replacement Registry; 2019. www.aoa.org.au. Accessed 19 Aug 2020.

9. Statistisches Bundesamt (DESTATIS). Staat \& Gesellschaft - Krankenhäuser Die 20 häufigsten Operationen insgesamt (OPS-Schlüssel 5) - Statistisches Bundesamt (Destatis). https://www.destatis.de/DE/ZahlenFakten/Gesellscha ftStaat/Gesundheit/Krankenhaeuser/Tabellen/DRGOperationen.html. Published 2018. Accessed 9 Oct 2018.

10. Bergen H. Norwegian National Advisory Unit on arthroplasty and hip fractures Norwegian arthroplasty register Norwegian cruciate ligament register Norwegian hip fracture register Norwegian Paediatric hip register. 2019. http://nrlweb.ihelse. Accessed 20 Aug 2020.

11. Registry NJ, for England W, And NI, Man the I of. 2019 16th Annual Report. www.njrreports.org.uk. Accessed 20 Aug 2020.

12. Inacio MCS, Graves SE, Pratt NL, Roughead EE, Nemes S. Increase in Total joint arthroplasty projected from 2014 to 2046 in Australia: a conservative local model with international implications. Clin Orthop Relat Res. 2017; 475(8):2130-7. https://doi.org/10.1007/s11999-017-5377-7.

13. Inacio MCS, Paxton EW, Graves SE, Namba RS, Nemes S. Projected increase in total knee arthroplasty in the United States - an alternative projection model. Osteoarthr Cartil. 2017;25(11):1797-803. https://doi.org/10.1016/j. joca.2017.07.022

14. Culliford D, Maskell J, Judge A, Cooper C, Prieto-Alhambra D, Arden NK. Future projections of total hip and knee arthroplasty in the UK: results from the UK clinical practice research datalink. Osteoarthr Cartil. 2015;23(4):594600. https://doi.org/10.1016/j.joca.2014.12.022.

15. Kahlenberg CA, Nwachukwu BU, McLawhorn AS, Cross MB, Cornell CN, Padgett DE. Patient satisfaction after Total knee replacement: a systematic review. HSS J. 2018;14(2):192-201. https://doi.org/10.1007/s11420-018-9614-8.

16. Beswick AD, Wylde V, Gooberman-Hill R, Blom A, Dieppe P. What proportion of patients report long-term pain after total hip or knee replacement for osteoarthritis? A systematic review of prospective studies in unselected patients. BMJ Open. 2012;2(1):e000435. https://doi.org/10.1136/bmjopen-2 011-000435.

17. Jones CA, Voaklander DC, Johnston DWC, Suarez-Almazor ME. Health related quality of life outcomes after total hip and knee arthroplasties in a community based population. J Rheumatol. 2000;27(7):1745-52.

18. Fransen M, Mcconnell S, Harmer AR, Van der Esch M, Simic M, Bennell KL. Exercise for osteoarthritis of the knee: a Cochrane systematic review. $\mathrm{Br} J$ Sports Med. 2015;49(24):1554-7. https://doi.org/10.1136/bjsports-2015095424.

19. Henderson KG, Wallis JA, Snowdon DA. Active physiotherapy interventions following total knee arthroplasty in the hospital and inpatient rehabilitation settings: a systematic review and meta-analysis. Physiother (United Kingdom). 2018;104(1):25-35. https://doi.org/10.1016/j.physio.2017.01.002.

20. Artz N, Elvers KT, Lowe CM, Sackley C, Jepson P, Beswick AD. Effectiveness of physiotherapy exercise following total knee replacement: systematic review and meta-analysis. BMC Musculoskelet Disord. 2015;16(1):15. https:// doi.org/10.1186/s12891-015-0469-6.

21. National Institute For Health And Care Exellence (NICE). Guideline - Joint replacement (primary): hip, knee and shoulder. https://www.nice.org.uk/ guidance/ng157/documents/draft-guideline. Accessed 31 Aug 2020.

22. Kolber MJ, Hanney WJ, Lamb BM, Trukman B. Does physical therapy visit frequency influence acute care length of stay following knee arthroplasty? A systematic review. Top Geriatr Rehabil. 2013;29(1):25-9. https://doi.org/10.1 097/TGR.0b013e3182767262

23. Westby MD, Brittain A, Backman CL. Expert consensus on best practices for post-acute rehabilitation after total hip and knee arthroplasty: a Canada and United States Delphi study. Arthritis Care Res. 2014;66(3):411-23. https://doi. org/10.1002/acr.22164.

24. Mistry J, Elmallah R, Bhave A, Chughtai M, Cherian J, McGinn T, et al. Rehabilitative guidelines after Total knee arthroplasty: a review. J Knee Surg. 2016;29(03):201-17. https://doi.org/10.1055/s-0036-1579670.

25. Naylor JM, Hart A, Harris IA, Lewin AM. Variation in rehabilitation setting after uncomplicated total knee or hip arthroplasty: a call for evidence-based guidelines. BMC Musculoskelet Disord. 2019;20(1). https://doi.org/10.1186/ s12891-019-2570-8.
26. Lange T, Luque Ramos A, Albrecht K, Günther KP, Jacobs H, Schmitt J, et al. Prescription frequency of physical therapy and analgesics before total hip and knee arthroplasy: an epidemiological analysis of routine health care data from Germany. Orthopade. 2018;47(12):1015-23. https://doi.org/10.1 007/s00132-018-3629-1.

27. Power JD, Cott CA, Badley EM, Hawker GA. Physical therapy services for older adults with at least moderately severe hip or knee arthritis in 2 Ontario counties. J Rheumatol. 2005;32(1):123-9.

28. McHugh GA, Luker KA, Campbell M, Kay PR, Silman AJ. A longitudinal study exploring pain control, treatment and service provision for individuals with end-stage lower limb osteoarthritis. Rheumatology. 2007;46(4):631-7. https://doi.org/10.1093/rheumatology/kel355.

29. Hofstede SN, Vlieland TPMV, Van Den Ende CHM, Nelissen RGHH, Marang-Van De Mheen PJ, Van Bodegom-Vos L. Variation in use of non-surgical treatments among osteoarthritis patients in orthopaedic practice in the Netherlands. BMJ Open. 2015;5(9). https://doi.org/10.1136/bmjopen-2015-009117.

30. King LK, Marshall DA, Faris P, Woodhouse LJ, Jones CA, Noseworthy T, et al. Use of recommended non-surgical knee osteoarthritis Management in Patients prior to Total knee arthroplasty: a Cross-sectional study. J Rheumatol. 2020;47(8):1253-60. https://doi.org/10.3899/jrheum.190467.

31. Moher D, Liberati A, Tetzlaff J, Altman DG, The PRISMA Group. Preferred reporting items for systematic reviews and meta-analyses: the PRISMA statement. PLoS Med. 2009;6(7):e1000097. https://doi.org/10.1371/journal. pmed.1000097.

32. Munn Z, Sandeep M, Lisy K, Riitano D, Tufanaru C. Methodological guidance for systematic reviews of observational epidemiological studies reporting prevalence and cumulative incidence data. Int J Evid Based Healthc. 2015; 13(3):147-53. https://doi.org/10.1097/XEB.0000000000000054.

33. Munn Z, Stern C, Aromataris E, Lockwood C, Jordan Z. What kind of systematic review should i conduct? A proposed typology and guidance for systematic reviewers in the medical and health sciences. BMC Med Res Methodol. 2018;18, 5(1). https://doi.org/10.1186/s12874-017-0468-4.

34. Munn Z, Moola S, Riitano D, Lisy K. The development of a critical appraisal tool for use in systematic reviews addressing questions of prevalence. Int J Health Policy Manag. 2014;3(3):123-8. https://doi.org/10.15171/ijhpm.2014.71.

35. Andersen $\mathrm{SH}$, Husted $\mathrm{H}$, Kehlet $\mathrm{H}$. Economic consequences of accelerated care pathways in total knee-arthroplasty. Ugeskr Laeger. 2009;171(45):3276-80.

36. Hamilton DF, Loth FC, MacDonald DJ, MacFarlane GJ, Beard DJ, Simpson AHRW, et al. Exploring variation in patient access of post-discharge physiotherapy following total hip and knee arthroplasty under a choice based system in the UK: an observational cohort study. BMJ Open. 2019; 9(2):e021614. https://doi.org/10.1136/bmjopen-2018-021614.

37. Han ASY, Nairn L, Harmer AR, et al. Early rehabilitation after total knee replacement surgery: a multicenter, noninferiority, randomized clinical trial comparing a home exercise program with usual outpatient care. Arthritis Care Res. 2015;67(2):196-202. https://doi.org/10.1002/acr.22457.

38. Smith TO, Dainty JR, Clark EM, Whitehouse MR, Price AJ, MacGregor AJ. Demographic and geographical variability in physiotherapy provision following hip and knee replacement. An analysis from the National Joint Registry for England, Wales, Northern Ireland and the Isle of Man. Physiother (United Kingdom). 2020;106:1-11. https://doi.org/10.1016/j. physio.2019.11.003.

39. Warren M, Shireman TI. Geographic variability in discharge setting and outpatient postacute physical therapy after total knee arthroplasty: a retrospective cohort study. Phys Ther. 2018;98(10):855-64. https://doi.org/1 0.1093/ptj/pzy077.

40. Fransen M, Nairn L, Bridgett L, Crosbie J, March L, Parker D, et al. Post-acute rehabilitation after Total knee replacement: a multicenter randomized clinical trial comparing long-term outcomes. Arthritis Care Res. 2017;69(2): 192-200. https://doi.org/10.1002/acr.23117.

41. Artz N, Dixon S, Wylde V, Beswick A, Blom A, Gooberman-Hill R. Physiotherapy provision following discharge after Total hip and Total knee replacement: a survey of current practice at high-volume NHS hospitals in England and Wales. Musculoskeletal Care. 2013;11(1):31-8. https://doi.org/1 0.1002/msc.1027.

42. Hart A, Bergeron SG, Epure L, Huk O, Zukor D, Antoniou J. Comparison of US and Canadian perioperative outcomes and hospital efficiency after total hip and knee arthroplasty. JAMA Surg. 2015;150(10):990-8. https://doi.org/1 0.1001/jamasurg.2015.1239.

43. The Royal Australasian College of Surgeons. Rehabilitation Following Hip and Knee Arthroplasty i Rehabilitation Pathways Following Hip and Knee 
Arthroplasty Final Report Rehabilitation Following Hip or Knee Arthroplasty:; 2018. www.surgeons.org. Accessed 4 Nov 2020.

44. Ong KL, Lotke PA, Lau E, Manley MT, Kurtz SM. Prevalence and costs of rehabilitation and physical therapy after primary TJA. J Arthroplast. 2015; 30(7):1121-6. https://doi.org/10.1016/j.arth.2015.02.030.

45. Seeber $\mathrm{GH}$, Wijnen $\mathrm{A}$, Lazovic $\mathrm{D}$, et al. Effectiveness of rehabilitation after a total hip arthroplasty: a protocol for an observational study for the comparison of usual care in the Netherlands versus Germany. BMJ Open. 2017;7(8). https://doi.org/10.1136/bmjopen-2017-016020.

46. Füssenich W, Gerhardt DMJM, Pauly T, Lorenz F, Olieslagers M, Braun C, et al. A comparative health care inventory for primary hip arthroplasty between Germany versus the Netherlands. Is there a downside effect to fast-track surgery with regard to patient satisfaction and functional outcome? HIP Int. 2020;30(4):423-30. https:/doi.org/10.1177/1120700019876881.

47. Herbert RD, Bø K. Analysis of quality of interventions in systematic reviews. Br Med J. 2005;331(7515):507-9. https://doi.org/10.1136/bmj.331.7515.507.

48. Dagfinrud H, Kvien TK, Hagen KB. Physiotherapy interventions for ankylosing spondylitis. Cochrane Database Syst Rev. 2008;1. https://doi.org/10.1002/14 651858.CD002822.pub3.

49. Green S, Buchbinder R, Hetrick SE. Physiotherapy interventions for shoulder pain. Cochrane Database Syst Rev. 2003;2003(2). https://doi.org/10.1002/14 651858.CD004258

50. Fransen M, McConnell S, Hernandez-Molina G, Reichenbach S. Exercise for osteoarthritis of the hip. Cochrane Database Syst Rev. 2014;4:CD007912. https://doi.org/10.1002/14651858.CD007912.pub2.

51. Rietberg MB, Brooks D, Uitdehaag BMJ, Kwakkel G. Exercise therapy for multiple sclerosis. Cochrane Database Syst Rev. 2009;2005(4). https://doi. org/10.1002/14651858.CD003980.pub2.

52. Tomlinson CL, Patel S, Meek C, et al. Physiotherapy versus placebo or no intervention in Parkinson's disease. Cochrane Database Syst Rev. 2013; 2013(9). https://doi.org/10.1002/14651858.CD002817.pub4.

53. Cooney GM, Dwan K, Greig CA, Lawlor DA, Rimer J, Waugh FR, et al. Exercise for depression: some benefits but better trials are needed. Saudi Med J. 2013;34(11):1203. https://doi.org/10.1002/14651858.CD004366.pub6.

54. Wijnen A, Bouma SE, Seeber GH, van der Woude LHV, Bulstra SK, Lazovic D, et al. The therapeutic validity and effectiveness of physiotherapeutic exercise following total hip arthroplasty for osteoarthritis: a systematic review. PLoS One. 2018;13(3):e0194517. https://doi.org/10.1371/journal.pone. 0194517.

55. Yeh $\mathrm{H}-\mathrm{J}$, Chou Y-J, Yang N-P, Huang N. Receipt of physical therapy among osteoarthritis patients and its influencing factors. Arch Phys Med Rehabil. 2015;96(6):1021-7. https://doi.org/10.1016/j.apmr.2015.02.006.

56. Jacobs H, Callhoff J, Hoffmann F, Zink A, Albrecht K. Non-drug treatment of rheumatoid arthritis: an analysis of claims data and a survey of insured persons (project PROCLAIR). Z Rheumatol. 2019;78(2):119-26. https://doi. org/10.1007/s00393-018-0567-6.

57. Rommel A, Kroll LE. Individual and regional determinants for physical therapy utilization in Germany: multilevel analysis of National Survey Data. Phys Ther. 2017;97(5):512-23. https://doi.org/10.1093/ptj/pzx022.

58. Lange U. Physiotherapie in der Rheumatologie. Z Rheumatol. 2015;74(8): 701-10. https://doi.org/10.1007/s00393-015-1588-z.

59. Carter SK, Rizzo JA. Use of outpatient physical therapy services by people with musculoskeletal conditions background and purpose. 2007;87(5):497512. https://doi.org/10.2522/ptj.20050218.

60. Iversen MD, Schwartz TA, von Heideken J, Callahan LF, Golightly YM, Goode A, et al. Sociodemographic and clinical correlates of physical therapy utilization in adults with symptomatic knee osteoarthritis. Phys Ther. 2018; 98(8):670-8. https://doi.org/10.1093/ptj/pzy052.

61. Jacobs H, Callhoff J, Albrecht K, et al. Use of physiotherapy in patients with osteoarthritis in Germany- an analysis of a linkage of claims and survey data (from the PROCLAIR project). Arthritis Care Res. 2020:acr.24365. https:// doi.org/10.1002/acr.24365.

62. Bourne RB, Chesworth B, Davis A, Mahomed N, Charron K. Comparing patient outcomes after THA and TKA: is there a difference? Clin Orthop Relat Res. 2010;468(2):542-6. https://doi.org/10.1007/s11999-009-1046-9.

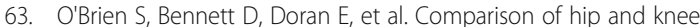
arthroplasty outcomes at early and intermediate follow-up. Orthopedics. 2009;32:168

64. Ethgen $\mathrm{O}$, Bruyere $\mathrm{O}$, Richy $\mathrm{F}$, et al. Health-related quality of life in total hip and total knee arthroplasty. A qualitative and systematic review of the literature. J Bone Joint Surg Am. 2004;86-A:963.
65. Wylde V, Blom AW, Whitehouse SL, Taylor AH, Pattison GT, Bannister GC. Patient-reported outcomes after total hip and knee arthroplasty: comparison of midterm results. J Arthroplast. 2009;24(2):210-6. https://doi. org/10.1016/j.arth.2007.12.001.

66. de Beer J, Petruccelli D, Adili A, Piccirillo L, Wismer D, Winemaker M. Patient perspective survey of Total hip vs Total knee arthroplasty surgery. J Arthroplast. 2012;27(6):865-869.e5. https://doi.org/10.1016/j.arth.2011.12.031.

67. Kimball CC, Nichols Cl, Nunley RM, Vose JG, Stambough JB. Skilled nursing facility star rating, patient outcomes, and readmission risk after Total joint arthroplasty. J Arthroplast. 2018;33(10):3130-7. https://doi.org/10.1016/j.a rth.2018.06.0.

\section{Publisher's Note}

Springer Nature remains neutral with regard to jurisdictional claims in published maps and institutional affiliations.
Ready to submit your research? Choose BMC and benefit from:

- fast, convenient online submission

- thorough peer review by experienced researchers in your field

- rapid publication on acceptance

- support for research data, including large and complex data types

- gold Open Access which fosters wider collaboration and increased citations

- maximum visibility for your research: over $100 \mathrm{M}$ website views per year

At BMC, research is always in progress.

Learn more biomedcentral.com/submissions 